\title{
A FORMAÇÁO do PEDAGOGO PARA ATUAR NO SISTEMA PENITENCIÁRIO
}

\author{
TEACHER EDUCATION TO ACT IN THE PENITENTIARY SYSTEM
}

\author{
Silvana Barbosa de Oliveira \\ Doutorado em Educaçáo pela Pontifícia Universidade Católica do Paraná - PUC/PR. \\ Pedagoga do Patronato Penitenciário do Paraná. Paraná - PR - Brasil \\ ORCID: https://orcid.org/0000-0003-0093-5677 \\ silvana.barbosa@depen.pr.gov.br
}

Resumo: A Educação prisional tem evoluído no campo educacional com a contribuição conceitual da Pedagogia Social. Este texto versa sobre a formação dos pedagogos que atuam no sistema penitenciário do estado do Paraná. Assim, definimos como objetivo específico deste artigo analisar a prática pedagógica desenvolvida pelos pedagogos que atuam em unidades penais para, entáo, perseguir o objetivo geral de sistematizar princípios orientadores para a sua formação. Desenvolve-se numa abordagem qualitativa, apoiada no eixo epistemológico da teoria como expressão da prática (MARTINS, 2009), e toma como objeto de estudo a formaçáo do pedagogo para o sistema prisional. Foram utilizados como instrumentos de coleta de dados o questionário semiestruturado e a entrevista episódica, aplicados a trinta e seis pedagogos dos regimes fechado, semiaberto e aberto do sistema penitenciário paranaense. Como referencial teórico foram adotadas concepções teorizadas por Brzezinski (1996); Garcia (2013); Gentili (1995); Julião (2012, 2014); Libâneo (2004); Martins (2009); Nóvoa (2014); Pimenta (2006); Romanowiski (2014); Saviani (2008, 2009), Silva (2003); Thompson (1981) e Vásquez (2007). O estudo possibilitou a sistematização de indicadores da formação do pedagogo para o sistema prisional: formação na e pela prática; afirmação da experiência como referência e da teoria como expressão da prática; estudos centrados nas especificidades do contexto prisional; formaçáo permanente direcionada e em articulaçáo com os demais profissionais que atuam nas unidades penais; formação de caráter político no sentido de assumir a condição de defensor dos direitos humanos em sua prática e na defesa do direito à educação.

Palavras-chave: Direitos Humanos. Educação Prisional. Formação de Professores.

Pedagogo. 
Aвstract: Prison education has evolved in the educational field with the conceptual contribution of Social Pedagogy. This text deals with the training of pedagogues who work in the penitentiary system of the state of Paraná. Thus, we define as a specific objective of this article to analyze the pedagogical practice developed by the pedagogues that work in penal units to pursue the general objective of systematizing guiding principles for their formation. It develops in a qualitative approach, based on the epistemological axis of the theory as an expression of the practice (MARTINS, 2009), and takes as object of study the formation of the pedagogue for the prison system. The semi-structured questionnaire and the episodic interview were used as data collection instruments, applied to thirtysix pedagogues of the closed, semi-open and open regimes of the Paraná penitentiary system. As theoretical reference were adopted conceptions theorized by Brzezinski (1996); Garcia (2013); Gentili (1995); Julião (2012, 2014); Libâneo (2004); Martins (2009); Nóvoa (2014); Pimenta (2006); Romanowski (2014); Saviani (2008, 2009), Silva (2003); Thompson (1981) and Vásquez (2007). The study made possible the systematization of indicators of the education of the pedagogue for the prison system: training in and by practice; affirmation of experience as a reference and of theory as an expression of practice; studies focusing on the specificities of the prison context; permanent formation directed and in articulation with the other professionals who work in the penal units; formation of a political character in the sense of assuming the condition of defender of human rights in its practice and in the defense of the right to education.

Keywords: Human Rights. Prison Education. Teacher training. Pedagogue.

\section{Introduçáo}

A formação do pedagogo que atua na educação prisional constitui problema complexo, dadas as características específicas do sistema prisional e suas múltiplas relações de ordem estrutural, financeira, física, jurídica, humana e política que impedem uma análise isolada. $\mathrm{O}$ universo recortado para análise neste artigo, o estado do Paraná, é basicamente didático, pois os elementos não se separam na realidade concreta.

Nesse contexto, emerge o pedagogo, cujo trabalho dentro de uma unidade penitenciária apresenta desafios de articulação e concretização dos processos de escolarização, qualificação e profissionalização, considerando ainda a questão do direito à educação, o número de vagas nas unidades penais, as dificuldades com a movimentação dos privados de liberdade, a relação de poder que perpassa o trabalho dos agentes penitenciários, a falta de recursos, entre outros.

Neste artigo, no âmbito da compreensão do sistema penitenciário como um todo e do trabalho do pedagogo, de modo particular, buscamos desencadear o processo de reflexão sobre essa realidade em sua relação com 
a realidade social mais ampla dos direitos humanos. Para perfazer esse caminho, tomamos como objeto de estudo a formação do pedagogo para atuar no sistema prisional, orientados pelo seguinte problema de pesquisa: Como se dá a constituição profissional do pedagogo que atua em unidades penais?

Para encaminhar a investigação, nos propusemos a estudar, por meio do processo histórico, os fundamentos teóricos, políticos, de formação e prática do pedagogo que atua em unidades penitenciárias. Assim, definimos como objetivo específico deste artigo analisar a prática pedagógica desenvolvida pelos pedagogos que atuam em unidades penais para, então, perseguir o objetivo geral de sistematizar princípios orientadores para a sua formação.

Partimos do pressuposto de que, para compreender o trabalho desenvolvido pelos pedagogos em outros espaços de educação formal e não formal, precisamos nos aproximar dele, vivenciá-lo e senti-lo na prática, como experiência que fornece as bases para apreendê-lo, o que representa uma investigação muito instigante. Nessa perspectiva, a educação prisional e o trabalho desenvolvido pelo pedagogo nesse espaço serão apresentados considerando sua formação e a sua prática pedagógica.

A complexidade que reveste o tema e suas implicaçóes são muito mais amplas e abrangentes do que, aqui, se poderia trabalhar. No entanto, apresentamos os resultados da pesquisa, fruto de investigação empírica e de busca de valorização do importante trabalho pedagógico realizado nas unidades penais e nas escolas da prisão.

\section{Percurso Metodológico}

Compreender a formação inicial e continuada do pedagogo no sistema penitenciário coloca a necessidade de conhecer todos os elementos que envolvem a sua prática e o desenvolvimento do seu trabalho com pessoas privadas de liberdade. Essa compreensão exige a utilização de um método que permita a compreensão científica do fenômeno, referencial teórico coerente e construção lógica fundamentada numa abordagem adequada a essa realidade. Exige também uma postura reflexiva que procure identificar nos discursos políticos e na prática desenvolvida por esses profissionais a interlocução entre teoria e prática. 
Existem diferentes paradigmas de interpretação da realidade, ou seja, diferentes abordagens para compreender como o homem se relaciona com as coisas, a natureza e a vida. Para esse estudo são utilizadas as categorias contradição, historicidade e totalidade como elementos metodológicos de interpretação da realidade do trabalho do pedagogo no sistema penitenciário paranaense. Tais categorias de método supôe a investigação da conexão entre a forma pela qual a sociedade produz sua existência material e a prática do pedagogo, que náo só reproduz, mas que também implica um movimento dialético em um contexto social no qual coexistem conflitos de interesses e embates permanentes inerentes ao modelo sociopolítico capitalista. Nesse embate de interesses opostos essas categorias se fazem necessárias para aprofundar o entendimento do objeto de estudo.

É assim que o recorte da pesquisa apresentado neste artigo buscou não apenas retratar a realidade do pedagogo, compreendendo sua relação e ação política no desenvolvimento do trabalho e no cumprimento de diretrizes, mas também desvelar a sua formação na e pela prática que desenvolve no seu trabalho, apoiada na concepção da teoria como expressão da prática. Portanto, de acordo com a natureza interpretativa do estudo, os instrumentos de coleta de dados constituíram-se de: i. dimensão bibliográfica, com a revisão de literatura realizada a partir de livros, teses, dissertaçôes, periódicos; ii. dimensão documental, com levantamento e análise de documentos legais, como os planos de acordos políticos nacionais e internacionais; iii. dimensão empírica, no uso de questionário e entrevista.

Dadas as peculiaridades da pesquisa e a necessidade de uma aproximação com o campo empírico, optamos por investigar o sistema penal do estado do Paraná, abrangendo os pedagogos que trabalham na área. De um universo de trinta e seis pedagogos que atuam hoje no sistema penitenciário do estado do Paraná, vinte deles participaram da pesquisa, totalizando $55,5 \%$ do total. Em função da localização espacial das 36 unidades penais, situadas em vários municípios do estado, houve dificuldade em contatar pessoalmente cada pedagogo, apesar de conhecê-los todos. Assim, foram enviados questionários via e-mail, com todos os dados necessários, inclusive o requerimento de aprovação de pesquisa de campo da Secretaria da Justiça, Cidadania e Direitos Humanos (SEJU)[1] do Departamento Penitenciário (DEPEN) e o termo de consentimento livre e esclarecido. Os dados apresentados pelos pedagogos que estão na ativa foram enriquecidos 
e agregados às informações dadas por dois pedagogos aposentados que atuaram no sistema penal do Paraná. Na forma de entrevista episódica, relataram também as questôes de sua formação e da prática desenvolvida nos espaços prisionais como servidores do DEPEN.

Os questionários foram organizados em três partes: a primeira com ênfase nos dados pessoais; a segunda, focava a formação profissional, e a terceira, o trabalho desenvolvido especificamente no sistema prisional. A opção pelo questionário teve como objetivo abranger o maior número possível de pedagogos participantes. As questôes sobre sua formação e experiência profissional possibilitaram organizar um quadro referencial do perfil desses pedagogos e as questóes abertas permitiram interpretar a relação entre sua formação e experiência no trabalho desenvolvido nas unidades penais.

As duas entrevistas foram gravadas e transcritas na íntegra, focando as situaçóes concretas nas quais os entrevistados viveram determinadas experiências. Apesar de um roteiro pré-elaborado, os entrevistados acabaram contando sua trajetória nas unidades de forma natural, o que foi respeitado pela entrevistadora, sem que se fugisse da proposta inicial da pesquisa.

A análise do conteúdo desses materiais produziu indícios e evidências sobre a formação dos pedagogos a partir de suas práticas, ou seja, os pedagogos aprenderam a ser pedagogos do sistema penal por meio da própria atividade - aprenderam a atuar, atuando. Foram conhecendo e adequando o seu trabalho a partir das experiências vivenciadas anteriormente na docência e na gestáo da Educação de Jovens e Adultos (EJA).

\section{Contextualizando o Sistema Penitenciário Paranaense}

O Sistema Penitenciário do Estado do Paraná é coordenado pelo Departamento Penitenciário do Estado do Paraná (DEPEN), órgão da Secretaria de Segurança Pública e Administração Penitenciária (SESP). SESP e DEPEN têm como compromisso social e institucional a custódia e recuperação dos indivíduos privados de liberdade, exercendo o dever de Estado de prover assistência (material, à saúde, jurídica, educacional, social e religiosa) e trabalho ao preso e ao egresso, objetivando prevenir o crime e orientar o retorno à convivência na sociedade. 
A Lei de Execuçôes Penais (LEP 7.210), de 11 de julho de 1984, estabelece que os estabelecimentos penais se destinam ao condenado, ao submetido a medida de segurança, ao preso provisório e ao egresso (BRASIL, 1984). Esses estabelecimentos são classificados de acordo com o seu regime: fechado, semiaberto e aberto.
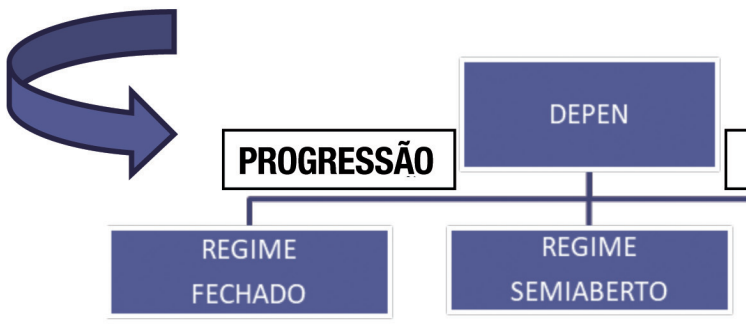

REGRESSÃO

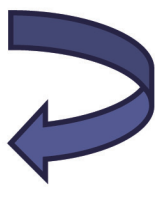

\section{SEMIABERTO}

REGIME ABERTO

Figura 1: Quadro esquemático dos regimes

Fonte: Depen/SESP. Elaboração da autora (2015).

I. Estabelecimentos Presidiários: destinam-se aos presos provisórios e aos sujeitos à prisão simples especial;

II. Estabelecimentos Penitenciários: destinam-se aos condena-

dos ao cumprimento da pena em regime fechado; to do condenado. Para tanto, se vale de uma avaliação realizada pela equipe técnica da unidade penal, segundo o Estatuto Penitenciário do Estado do Paraná, juntamente com os demais membros do Conselho Disciplinar (CD)[2] e da Comissão Técnica de Classificação (CTC)[3] os quais fundamentam um relatório para subsidiar a formação da livre convicção do magistrado.

Assim, passa-se de uma fase para outra conforme as condutas e as respostas mais socializadas, inclusive na definição de encaminhamento para a escola ou para o trabalho, de acordo com o estabelecimento penal. O Estatuto Penitenciário do Estado do Paraná define os estabelecimentos penais de acordo com os regimes de execução penal: progrida de um regime para outro, ou regrida, pois é um programa gradual de cumprimento da privação da liberdade segundo o méri- 
III. Estabelecimentos Agrícolas, Industriais ou Mistos: destinam-se aos condenados ao cumprimento da pena em regime semiaberto;

IV. Estabelecimentos Médico Penais: compreendem o Hospital Penitenciário, destinado ao tratamento médico ou cirúrgico de presos e internados; Hospital de Custódia e Tratamento Psiquiátrico, destinado ao cumprimento das medidas de segurança e ao tratamento psiquiátrico, separadamente; e sanatório, destinado ao recolhimento dos presos ou internados portadores de moléstia infectocontagiosas;

IV. Centro de Observação Criminológica e Triagem: destina-se a realização dos exames gerais e criminológico determinados em decisôes judiciais (regime fechado); segurança e custódia temporária de pessoas de ambos os sexos internadas por mandado judicial para exame e triagem; realização de audiências de advertência de livramento condicional e o fornecimento de carteiras aos liberados nesse regime e no regime aberto;

V. Patronato: destinam-se a assistência aos que cumprem pena em regime aberto, aos liberados condicionais, aos egressos e aos seus familiares. (PARANÁ, 1995)

A LEP prevê que é dever do Estado a assistência ao preso e ao internado e essa assistência deve estender-se também ao egresso (aqueles que saíram do regime fechado ou semiaberto e progrediram para o regime aberto).

O pedagogo responsável pela assistência educacional no sistema penitenciário paranaense desenvolve atividades em conjunto com a equipe técnica, assim como atividades específicas de escolarização, qualificação e profissionalização dos apenados.

\section{Educação no sistema penitenciário do Paraná}

O Conselho Nacional de Política Criminal e Penitenciária (CNPCP), por meio da Resolução no 14, de 11 de novembro de 1994, editou as Regras Minimas para o Tratamento do Preso no Brasil, fruto de decisóes tomadas em 
congressos internacionais sobre justiça penal. O referido texto, em seu capítulo XII, aborda a instrução e assistência educacional, definindo o seguinte:

Art. 38. A assistência educacional compreenderá a instrução escolar e a formação profissional do preso.

Art. 39. O ensino profissional será ministrado em nível de iniciação e de aperfeiçoamento técnico.

Art. 40. A instrução primária será obrigatoriamente ofertada a todos os presos que náo a possuam.

Parágrafo Único - Cursos de alfabetização serão obrigatórios e compulsórios para os analfabetos.

Art. 41. Os estabelecimentos prisionais contarão com biblioteca organizada com livros de conteúdo informativo, educativo e recreativo, adequado à formação cultural, profissional e espiritual do preso. Art. 42. Deverá ser permitido ao preso participar de curso por correspondência, rádio ou televisão, sem prejuízo da disciplina e da segurança do estabelecimento. (BRASIL, 1994)

Destaque para o artigo 40, que indica a instrução primária como obrigatória e os cursos de alfabetização como compulsórios para os analfabetos, o que indica uma 'correção' necessária, beneficiando aqueles que nunca frequentaram a escola. Contudo, indica também a grave condição de adultos que não tiveram concretizado o seu direito à Educação na idade certa.

A Resolução no03/2009 do Conselho Nacional de Política Criminal e Penitenciária (CNCP), homologada pelo Ministério da Educação por meio da Resoluçáo no 2, de 19 de maio de 2010, do Conselho Nacional de Educação (CNE), estabelece as diretrizes nacionais para a oferta de educação nos estabelecimentos penais, considerando que as ações educativas deverão estar calcadas na Legislação Educacional vigente e na LEP (BRASIL, 2010). Visando atender a educação básica e a qualificação profissional, o Setor de Educação e Capacitação, vinculado à Divisão de Educação e Produção (DIEPRO) do DEPEN, desenvolve uma série de programas, projetos e açóes educacionais, com metodologias presencial e a distância, que têm o objetivo de viabilizar a educação básica, a qualificação profissional, a remição pela leitura e pelas açóes culturais e de esporte às pessoas privadas de liberdade no estado do Paraná. 
Essa oferta educacional foi efetivada a partir de 1982, fruto da parceria expressa em Resolução Conjunta, estabelecida entre a Secretaria de Estado da Educação e a Secretaria de Estado da Segurança Pública e Administração Penitenciária, de acordo com o disposto no Plano Estadual de Educação no Sistema Prisional do Paraná (PEESP), que atende às diretrizes nacionais e estaduais. $\mathrm{O}$ sistema penitenciário paranaense conta com nove Centros Estaduais de Educaçáo Básica para Jovens e Adultos (CEEBJAs), criados exclusivamente para atender aos estabelecimentos prisionais, os quais desenvolvem a proposta pedagógica aprovada pelo Conselho Estadual de Educação, conforme Parecer do Conselho Estadual de Educação CEE/CEIF/CEMEP No 02/14.

Nos estabelecimentos prisionais são ofertados exames estaduais e nacionais, nos seguintes formatos: 1. exames online oferecidos pela Secretaria de Estado da Educação do Paraná, que possibilitam a conclusão do Ensino Fundamental e do Ensino Médio, realizados anualmente nos estabelecimentos prisionais que possuem telecentro/laboratório de informática; 2. Exame Nacional para Certificação de Competências de Jovens e Adultos (ENCCEJA-PPL), organizados pelo Instituto Nacional de Estudos e Pesquisas Educacionais Anísio Teixeira (INEP), que possibilita a certificação do Ensino Fundamental e/ou do Ensino Médio; 3. Exame Nacional do Ensino Médio (ENEM-PPL), também ofertado pelo INEP, sendo realizado em todos os estabelecimentos prisionais do Paraná.

A qualificação profissional é realizada por meio de parcerias sociais, ou seja, sem ônus para o Estado, formalizadas por meio de convênios. Essas açôes são desenvolvidas pelo Setor de Educação e Capacitação/ DIEPRO/DEPEN, visando a qualificação e aperfeiçoamento profissional aliados à educação tecnológica e cursos livres de curta de média duração. Os CEEBJAs gerenciam todo o processo de matrícula e certificação nas unidades prisionais e são autorizados pelo Conselho Estadual de Educação do Paraná (CEE/PR).

\section{O pedagogo na unidade penal}

A educação como prática social historicamente construída constitui o sujeito, ao mesmo tempo em que é por ele constituído: "Pela investigação 
o homem transforma a Educação, que, por sua vez, transforma o homem (é o processo de investigação). A Educação é móvel (é prática social histórica), que se transforma pela ação dos homens em relação." (PIMENTA, 2006, p. 43) Nesse sentido, a Educação é uma ciência prática que jamais pode ser captada em sua integralidade, mas sim na dialética, por meio da ação dos educadores que, referendados na sua prática, elaboram conhecimentos que contribuem para alterar a prática existente.

Na defesa da concepção da Pedagogia como ciência de relação dialética com a prática Schmied-Kowarzik (1983) afirma que a relação entre teoria e prática é fundamental para a Pedagogia, pois está presente na prática educativa, na pesquisa em educação e na formação de professores. Nessa perspectiva, a concepção de Pedagogia como ciência prática, a Educação é entendida como processo de humanização do homem, e por práti

Designa-se originalmente toda atividade humana diferenciada de qualquer comportamento natural. E justamente porque a prática não ocorre de modo imediato e sem intermediação, requerendo uma decisão consciente, acaba sempre incluindo elementos teóricos. Por isso pode-se dizer que a prática exige uma teoria que a constitua e dirija... Assim a prática se torna fundamento e referência da verdade da teoria que a reflete. (SCHMIED-KOWARZIK, 1983, p.20-21)

Dessa forma, segundo o autor, a teoria náo pode objetivar a si mesma, se não uma realização efetiva de uma atividade humana, uma ciência da práxis e para a práxis, da ação do homem sobre e com os outros homens na busca da humanização - libertação e emancipação. No contexto dos problemas educacionais ligados à exclusão e ao atendimento de grupos vulneráveis, as discussōes e proposiçōes de uma Pedagogia Social vêm tomando corpo nas últimas décadas. Neste trabalho, ao tomar como objeto de estudo a formação do pedagogo para atuar no sistema penal, faz-se necessário considerar as teorizaçóes e pesquisas nesse campo. Silva, Souza Neto e Moura (2014, p. 285) consideram a Pedagogia Social como parte da Teoria Geral da Educação, devendo, nesse sentido, formar o pedagogo social em cursos de graduação em Pedagogia Social, com habilitaçōes específicas para: Educação Rural, Educação no Campo, Educação 
Hospitalar, Educação em Saúde, Educação em regimes de privação de liberdade, Educação de pessoas em situação de rua etc.

Considerando a insuficiência de estudos e de produção acadêmica sobre o pedagogo no sistema penal, defendemos que será a partir da prática que poderemos apreender elementos que sustentem a ação do pedagogo. Nesse sentido, tomamos Thompson (1981) e Martins (2009) para justificar essa opção pela epistemologia da prática, a partir da categoria da experiência. Os pedagogos que atuam nas unidades penais trazem consigo um referencial traduzido pelas suas experiências na docência, na coordenação, na gestão, no cotidiano, na prática do exercício profissional. No trabalho desenvolvido com os sujeitos privados de liberdade aprendem sobre a educação prisional, suas características e possibilidades, bem como a relação entre a legislaçáo penal e a educacional.

O setor pedagógico da unidade penal deve ser coordenado, necessariamente, por um profissional pedagogo, devidamente concursado e sendo profissional efetivo da Secretaria de Estado da Educação e com experiência em Educação de Jovens e Adultos. As atividades relacionadas à educação formal são desenvolvidas pelos pedagogos das unidades penais em parceria com o pedagogo do CEEBJA. Ambos os pedagogos atuam em direçáo à escolarização formal, com enfoques distintos na responsabilização das ações pedagógicas. Para entender essa relação, enumeramos as atividades de educação formal que estão sob a responsabilidade do pedagogo da unidade penal:

Conhecer, acompanhar e opinar sobre o projeto político pedagógico elaborado pela SEED para os CEEBJA bem como sobre os recursos oriundos do fundo rotativo destinados ao CEEBJA que atende a unidade penal; b) Conhecer, discutir e propor com o pedagogo do CEEBJA a definição de oferta de disciplinas na unidade penal, o planejamento curricular, bem como o calendário escolar; c) Acompanhar, opinar e aprovar a carga horária do corpo docente na unidade penal; d) Participar de reuniōes pedagógicas junto com os professores para discutir os temas que devem ser trabalhados com os alunos, voltados à conscientização sobre valores sociais (cidadania, drogas, ética, família, saúde, respeito, etc.); e) Acompanhar o desempenho escolar dos alunos, em 
grupo e individualmente, propondo medidas, em conjunto com os professores e pedagogo do CEEBJA, quando não corresponderem ao resultado esperado; f) Acompanhar o processo de matrículas dos alunos realizado pelo CEEBJA, respeitando os critérios definidos pelo DEPEN; g) Propor a reativação da matrícula de alunos que daráo continuidade aos estudos, aproveitando a carga horária e os registros de notas obtidas; h) Manter arquivado no Setor Pedagógico o Plano de Ação Pedagógica por disciplina, para facilitar o seu acompanhamento; i) Propor temas a serem desenvolvidos no âmbito das disciplinas ofertadas pela escola ou de projetos especiais, que atendam às necessidades do preso e da unidade penal, no sentido de colaborar para a compreensão do processo de marginalização social e para a desconstrução de um comportamento criminoso; j) Promover atividades extracurriculares em conjunto com o corpo docente da escola e ou com a equipe técnica da unidade, tais como a programaçâo de eventos de teatro, música, leitura jogos de saláo, artísticos, etc.; k) Propor metodologias alternativas ao trabalho do professor, utilizando-se de filmes, música, jogos, etc.; l) acompanhar a frequência e o horário das atividades docentes das unidades penais, conforme determina portaria do DEPEN; m) Propor e acompanhar a reposição de aulas, no caso de faltas, por meio de solicitação ao professor de um plano de reposição, que contemple a carga horária, dias, metodologia e conteúdo; n) Acompanhar e justificar a falta dos alunos que estiverem frequentando a escola quando se tratar de portarias, autorização de saídas temporárias, conselho disciplinar, audiência, doença, etc.; o) Articular junto aos órgãos responsáveis, inscrever os alunos e acompanhar os exames de suplência, bem como o ENEM; p) Organizar espaço para biblioteca escolar, propor critérios para o seu acesso por todos os presos da unidade, bem como pelos funcionários; q) Acompanhar, junto ao CEEBJA, critérios para o rodízio de professores; r) Realizar triagem (ainda que superficial) nas áreas visual e auditiva, para diagnosticar possíveis causas da dificuldade de aprendizagem; s) Elaborar e manter atualizada a listagem de presos que frequentam a escola para o Setor de Segurança; t) Manter, no Setor, um 
livro de ocorrências, e no caso de algum registro, comunicar ao Setor de Segurança; u) Orientar os professores sobre materiais permitidos ou não para utilização nas atividades docentes; v) Orientar, em conjunto com o Setor de Segurança, os professores novos sobre as normas de procedimentos e medidas de segurança no desempenho de suas funçôes na escola, bem como atualizar o corpo docente quando da mudança de qualquer norma que venha a interferir no trabalho escolar; w) Comunicar ao Setor de Segurança quando da falta de um preso a aula que não tenha justificativa. (FERREIRA; VIRMOND, 2011, p. 87-88)

Esse extenso rol de atividades a serem desenvolvidas pelo pedagogo nas unidades penais exige articulaçáo permanente com os demais técnicos (advogados, psicólogos, assistente social), a segurança (agentes de segurança), a direção e as diferentes e diversas instituiçóes educacionais, da rede pública e privada, e os professores e pedagogos do CEEBJA. O pedagogo, além de ser o articulador da educação formal na escola, também atende formação profissional e empregabilidade, por meio de cursos profissionalizantes, considerando as aptidóes pessoais, o nível de escolaridade e as condiçôes físicas da unidade penal. No regime aberto, o pedagogo acompanha os egressos do sistema penal e beneficiários de penas e medidas alternativas a prisão, e desenvolve atividades de apoio, encaminhamento e fiscalização da medida educativa na forma de encaminhamento para a educação formal, cursos profissionalizantes, palestras e grupos de reflexão, de acordo com as especificidades de cada município e as possíveis parcerias realizadas. (Figura 2)

As atividades orgânicas são aquelas realizadas pelo pedagogo da unidade penal e incluem os seguintes organismos e atividades: Conselho Disciplinar (CD), Comissão Técnica de Classificação (CTC), Parecer Específico do Complexo Médico Penal, Parecer para Benefícios, Avaliação Técnica, Entrevista de Triagem, Alimentação do SPR (Sistema de Processamento de Informaçóes) e Atividades de Grupo. Essas atividades são desenvolvidas individualmente, ou em grupo, com os demais profissionais, conforme as recomendaçôes para cada caso, e estáo relacionadas às questóes legais presentes na LEP e regulamentadas pelo Estatuto Penitenciário do Paraná. 


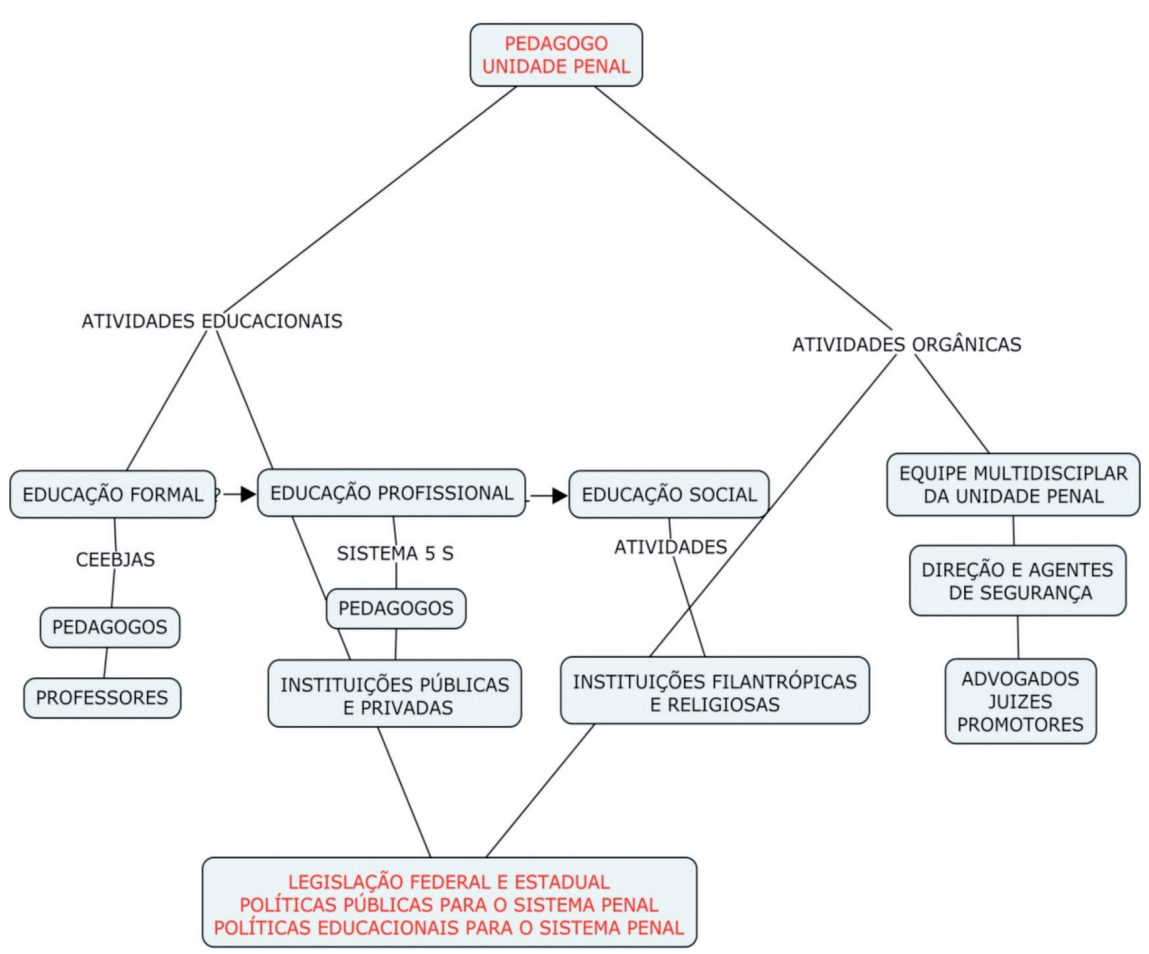

Figura 2: Mapa conceitual esquemático da prática pedagógica Fonte: Depen/SESP. Elaboração da autora (2015).

O pedagogo da unidade penal, ao participar da Comissão, deverá colaborar no sentido de levar para a reunião as informaçóes coletadas e a proposta de inclusão na escola, no programa de qualificaçáo e/ou atividade extracurricular. Os pareceres elaborados por ele constituem também atividades orgânicas; são documentos solicitados pelo diretor da unidade ou pelo juiz, para informaçóes e/ou concessão de benefícios.

As entrevistas de triagem ocorrem em todos os regimes, sendo o primeiro contato com o preso no regime fechado e semiaberto e com os egressos e beneficiários de penas alternativas no meio aberto.

Finalmente, as atividades em grupo (FERREIRA; VIRMOND, 2011) são realizadas pelo pedagogo de forma individual ou em conjunto com os outros técnicos da unidade, visando o acompanhamento, atendi- 
mento à solicitação do juiz ou atividade de cunho social proposta na individualização da pena, entre as quais podemos elencar: reunião de acolhimento, quando da chegada do apenado, para informar sobre as atividades existentes, a escola, os cursos e as possibilidades de participação; reunióes educativas para os privados de liberdade submetidos ao $\mathrm{CD}$; reunióes para informar sobre o mercado de trabalho, canteiros[4], cursos profissionalizantes; reunião para preparaçáo para a liberdade, informando como ele poderá dar continuidade aos estudos, sobre a existência do regime aberto representado pelo Patronato Penitenciário e seus serviços. Vale lembrar que essas atividades propostas nem sempre são realizadas, dado que várias das que aqui foram citadas exigem a participação de outros profissionais da equipe técnica, bem como a presença dos agentes de segurança para realizarem a movimentação dos privados de liberdade aos espaços definidos para realização das atividades.

No regime aberto o pedagogo atende os egressos oriundos do sistema penal e os beneficiários de penas e medidas alternativas à prisão, realizando a entrevista de triagem e procedendo aos encaminhamentos para a escola e cursos profissionalizantes, conforme a condição da sentença judicial imposta para cada caso. Realiza ainda o acompanhamento dos beneficiários de pena ou medida alternativa, no que se refere à escolarização e profissionalização; elabora informes ao juizado correspondente, quando solicitado, sobre o cumprimento das obrigaçóes impostas na condição do benefício, se for o caso de escolarização e profissionalização; propõe parcerias e acompanha programas de colocação profissional.

Importante frisar que apesar de haver uma rotina de atividades de trabalho já especificada para o pedagogo, ela está sempre de acordo com as condiçôes de segurança da unidade, ou seja, as atividades podem ser suspensas a qualquer tempo e a qualquer hora, por determinação da chefia de segurança, sempre que houver necessidade, visando assegurar a integridade física de todos.

\section{O pedagogo no sistema penal: formação e experiência}

Partimos do pressuposto de que a educação é desenvolvida sob as linhas do sistema econômico, que acaba por determinar, em boa medida, 
os fins e as diretrizes educacionais na forma de políticas públicas para organização, financiamento, provimento de professores e, também, para sua formação. Contudo, esse processo não é estático, há um embate de forças nesse movimento, ao mesmo tempo em que a educação sofre os efeitos dessa sociedade capitalista, ela provoca alterações, há um movimento dialético, de pensamento e ação, teoria e prática. "É a luta que dá a imprevisibilidade, que acaba com o sentido teleológico, que dá dinamismo e mostra as contradiçôes. É uma ação prática material e social determinante do processo." (MARTINS, 2011, p. 88)

Posicionando-se em favor da necessidade da alteração das relaçôes lógicas entre teoria e prática, pensamento e ação, Santos (1992, p. 82) afirma que o processo de atividade náo é resultado do processo de pensamento, e sim da prática. "A atividade humana é prática, distinta tanto do mundo das ideias quanto do mundo material. Ela se autonomiza e, ao mesmo tempo, se historiciza, definindo-se como criadora de instituiçóes." A defesa do autor é que a ação humana deve ser concebida como uma ação prática, que se realiza nas relaçóes sociais e institucionais e que "o conhecimento é sempre o conhecimento de uma prática, nunca da realidade natural ou social." (op.cit., p. 29) Assim, para ele, o modelo epistemológico adotado é o da teoria como expressão da prática e da concepção da teoria econômica burguesa como expressão da prática dos capitalistas.

Igualmente, na relação entre teoria e prática que emerge das discussôes entre os educadores a partir dos anos 80 podemos identificar dois grupos "comprometidos numa mesma unidade de perspectiva (visão crítica da educação)" (MARTINS, 2011, p. 85), um deles que toma como concepção a teoria como guia de ação prática, o outro que assume a concepção da teoria como expressão da ação prática.

A despeito dessas consideraçóes e da prática desenvolvida pelos pedagogos, assumimos a concepção da teoria como expressão da ação prática para responder à nossa problemática de definir "como e onde se dá a constituição profissional do pedagogo que atua nas unidades penais"? Essa constituição profissional refere-se à sua formação inicial e continuada, bem como a trajetória de experiência prática vivenciada como pedagogo na docência e na gestáo em espaços de educaçáo formal e não formal.

Portanto, essa forma de pensar dos homens não está dissociada da experiência que, nos termos de Thompson (1981, p. 16), é válida e efe- 
tiva: "A experiência surge espontaneamente no ser social, mas não surge sem pensamento. Surge porque homens e mulheres (e não apenas filósofos) são racionais e refletem sobre o que acontece a eles e ao seu mundo.” Reiteramos que esse ser social não se separa daquilo que pensa, da sua consciência social, do que experimenta, de modo que:

Não podemos conceber nenhuma forma de ser social independentemente de seus conceitos e expectativas organizadoras, nem poderia o ser social reproduzir-se por um único dia sem o pensamento. O que queremos dizer é que ocorrem mudanças no ser social que dão origem à experiência modificada: e essa experiência é determinante, no sentido de que exerce pressóes sobre a consciência social existente, propóe novas questóes e proporciona grande parte do material sobre o qual se desenvolvem os exercícios intelectuais mais elaborados. (id.ib.)

Essa experiência modificada que se apresenta e que propóe novas questôes identifica o movimento dialético que será proposto para a análise da formaçáo do pedagogo que atua no sistema prisional. O nosso pressuposto é que as experiências vivenciadas anteriormente nos espaços escolares, na coordenação e gestão forneceram a base para a atuação do pedagogo no sistema penal.

Assim, a relação teoria e prática está presente no pressuposto da experiência como um movimento dialético, pois o pedagogo, ao mesmo tempo em que sofre as implicaçôes do espaço da unidade penal onde atua, também transforma esses espaços com a sua prática. Portanto, a teoria como expressão da prática, posição por nós assumida, entende a educação como direito do ser humano e como transformaçáo social, no sentido de que "Educação e mudança social estâo intimamente relacionadas. A Educação permite aos indivíduos uma participação consciente na transformação da realidade social.” (SANTOS, 1992, p.116)

Dessa forma, as práticas pedagógicas não estão dissociadas desse movimento mais amplo, o significado de prática pedagógica transcende a questão da experiência como referida exclusivamente ao espaço de trabalho. O conceito de prática, conforme pensada por Sacristán (2014), não se limita às questóes metodológicas, ao espaço escolar e às açóes dos pro- 
fessores. O autor propóe o sistema de práticas aninhadas, ou seja, vários contextos incluídos uns nos outros. Ele explica:

Existe uma prática educativa e de ensino, em sentido antropológico, anterior e paralela à escolaridade própria de uma determinada sociedade e cultura. Nesse ambiente cultural, desenvolvem-se as práticas escolares institucionais, entre elas práticas relacionadas com o funcionamento do sistema escolar [...] práticas de índole organizativa [...] práticas didáticas e educativas [...] Além disso, fora do sistema educativo, realizamse atividades práticas que, não sendo estritamente pedagógicas, podemos considerar concorrentes das atividades escolares. (SACRISTÁN, 2014, p.69)

Nesse sentido, quando nos referimos à prática do pedagogo, estamos entendendo esse complexo sistema de práticas, que no sistema penitenciário se torna mais visível em virtude de suas especificidades e da equipe multiprofissional com a qual o pedagogo atua.

A prática do pedagogo, seu trabalho diário, está subordinada a oudes de ação do pedagogo dentro da unidade penal, pois elas dependem da ação dos agentes penitenciários. Os agentes penitenciários são os responsáveis pela movimentação dos apenados, para levá-los e trazê-los para a sala de aula e/ou outros espaços da unidade penal para realização de atividades, para os regimes fechado e semiaberto.

Enquanto categoria, a experiência representa mais do que a repetição de ações e práticas determinadas no conformismo do trabalho cotidiano; ela vai além, no sentido de proporcionar condiçóes para novas aprendizagens a partir de uma experiência anterior. Positiva ou negativa, a experiência que impulsiona a reflexáo sobre a prática também opera no sentido de propiciar diferentes respostas às novas situaçóes. Para nós, a experiência é um movimento dinâmico, a teoria e a prática são incorporados à prática na medida em que esses conhecimentos dão suporte para novas experiências, num movimento dialético, de ir e vir, de aprender e reaprender. Dessa forma, os pedagogos trazem suas experiências anteriores, da escola ou do meio aberto, para a realidade prisional, o que 
propicia atuar no sistema penitenciário. Ressalte-se que a experiência não se completa, está em permanente processo de novos conhecimentos e de novas práticas, fruto das relaçôes históricas de um determinado espaço de tempo: "O passado humano não é um agregado de histórias separadas, mas uma soma unitária do comportamento humano, cada aspecto do qual se relaciona com outros de determinadas maneiras, tal como os atores individuais se relacionam de certas maneiras [...]" (THOMPSON, 1981, p. 50)

Para pensar a formação e a experiência, tomamos como referência, inicialmente, a idade dos pedagogos participantes, para buscar uma relação entre a sua formação inicial e a formação continuada, bem como o tempo de experiência, para cotejá-los à prática desenvolvida nos espaços prisionais. Duas faixas etárias apresentaram o mesmo escore: $25 \%$ para a faixa de $45-49$ anos e $25 \%$ para a faixa de 50-54 anos, portanto, metade dos pedagogos participantes possui mais de quarenta e cinco anos de idade, indicando que não são profissionais jovens que atuam nos espaços prisionais e reforçando a necessidade da experiência para a atuação.

Esses dados apresentados sobre a idade dos pedagogos que participaram da pesquisa reforçam as exigências relatadas anteriormente sobre a contratação de pedagogos para atuarem no sistema penal: exigência de pertencer ao Quadro Próprio do Magistério (QPM) da Secretaria de Estado da Educação do Paraná (SEED), ter participado de edital de seleção específico para atuação em presídios e comprovação de experiência com a EJA. Essas exigências explicam porque a faixa etária desses pedagogos indica que não são profissionais recém-formados, ao contrário, possuem no mínimo cinco anos de experiência, o que representa um diferencial, uma vez que atuarão com as questôes específicas da educação e da segurança no sistema prisional. Idade e experiência prática alcançadas no número de anos dedicados à docência e/ou a gestão expressam a relação entre teoria e prática que assumimos, revelando-se como o diferencial no desenvolvimento das atividades diárias nas unidades penais.

O regime de atuação dos pedagogos corresponde ao número de unidades penais nas quais predomina o regime fechado. Assim, temos $75 \%$ deles, a maioria, atuando no regime fechado; $25 \%$ no semiaberto e um pedagogo do regime aberto, o que corresponde a $0,75 \%$. 


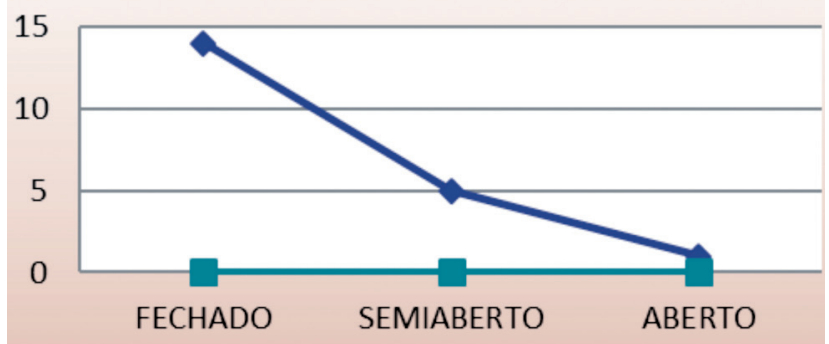

Gráfico 1: Regime de atuação dos pedagogos no sistema penal

Fonte: Depen/Coordenação de Educação e Profissionalização de Apenados, 2015.

Elaboração da autora.

Verifica-se que todos os pedagogos participantes têm graduação em Pedagogia, exigência para a função, a maioria deles com sua formação inicial concluída no estado do Paraná, sendo onze em instituiçôes públicas e quatro na rede privada, assim distribuídos: nove nas instituiçôes públicas, quatro pedagogos realizaram sua graduação na Universidade Federal do Paraná, três na Universidade Estadual de Londrina, dois na Faculdade Estadual de Filosofia, Ciências e Letras de Jacarezinho; nas privadas, foram dois concluintes na Pontifícia Universidade Católica do Paraná.

A prática pedagógica desenvolvida diariamente pelos pedagogos no sistema penal tem como referência suas experiências anteriores em termos de práticas e estudos vivenciados, que vão se modificando à medida que novas práticas se consolidam e proporcionam uma reflexão teórica que expressa essa prática.

\section{Indicadores e propostas de formação}

A proposta que defendemos para a formação dos pedagogos baseia-se na epistemologia defendida por Martins (2009) de que a teoria é expressão da prática, isto é, de açôes práticas. Portanto, o primeiro indicador analisa a relaçáo teoria e prática, constatando que a formaçáo do pedagogo que atua nas unidades penais se dá na e pela prática, toma como referência a experiência e afirma a teoria como expressão da prática. Nessa perspectiva, 
a formação dos pedagogos que atuam no sistema penal ocorreu na prática, aprenderam a ser pedagogos atuando nas unidades penais, tomando como base a experiência vivenciada em outros espaços da educação formal e não formal. Essa assertiva não desconsidera a necessidade de formação para esses profissionais, ao contrário, conhecer as características da educação carcerária requer conhecimentos e habilidades específicas para a sua atuação e para o desenvolvimento adequado de práticas pedagógicas voltadas a sujeitos privados de liberdade.

Um segundo indicador de uma formação que atenda as especificidades do sistema penal é a formação permanente, direcionada, atualizada e que articule concretamente mudanças e melhorias às práticas desenvolvidas. A atividade teórico-prática é na verdade a práxis, que dá a concretude às relaçôes. Vásquez (2007), apoiado em Marx, afirma que toda práxis é uma atividade, mas nem toda atividade é práxis. O que significa dizer que a formação do pedagogo precisa avançar para além da compreensão da valorização do processo prático, condição essa necessária para a verdadeira práxis.

A prática é considerada, nesse sentido, como elemento constituinte do fazer pedagógico, e a educação entendida como prática social. Decorre que a formação do pedagogo, nesses termos, indica a necessidade de contemplar os conhecimentos específicos da educação de jovens e adultos privados de liberdade. A formação do pedagogo que assume a condição de educação como humanização compreende que a sua prática pedagógica implica outras práticas, que acontecem no mesmo espaço, de forma que o pedagogo náo pode estar isolado das demais áreas que atuam juntas na execução penal. É necessária uma formação na qual agentes penitenciários, professores e pedagogos possam estar juntos, dessa forma propiciando o reconhecimento da importância de cada profissional que atua sistema prisional. Tal ambiente oportunizará uma formação em que o pedagogo possa contar com um planejamento realizado de maneira coletiva e colaborativa, visando traçar encaminhamentos comuns às diversas áreas e buscando conferir unidade nas açôes propostas.

Cada vez mais a Pedagogia Social faz parte da linguagem atual e é chamada a atuar como proposta para a busca de soluçáo dos problemas educacionais ligados à exclusão, às desigualdades educacionais e ao atendimento de grupos vulneráveis. 
Finalmente, a formação do pedagogo precisa contemplar e atender ao seu caráter político, no sentido de assumir, em sua prática, a condição de defensor dos direitos humanos e a defesa do direito à educação para todos os presos. A humanização do homem num espaço desumanizador.

\section{Notas}

1 No ano de 2015 o Departamento Penitenciário migrou da Secretaria de Justiça, Cidadania e Direitos Humanos para a Secretaria de Segurança Pública e Administração Penitenciária.

2 No Paraná, as disposições são regulamentadas no Estatuto Penitenciário, que em seu artigo 67 prevê a existência de um Conselho Disciplinar em cada estabelecimento penal. Esse Conselho deve ser presidido pelo diretor da unidade e composto por um secretário, um defensor e quatro técnicos: um psicólogo, um assistente social, um profissional de laborterapia e um da pedagogia.

3 Instituída pelo Art. 60 da Lei de Execuçôes Penais, a CTC é a responsável pela elaboração do programa para a individualização da pena e indicação do tratamento penal adequado a cada preso. Para tanto, deve contar com uma equipe multidisciplinar composta, no mínimo, por psiquiatra, psicólogo e assistente social. Embora não haja previsão legal a fim de dar maior abrangência a essa comissão, profissionais de pedagogia, terapia ocupacional e setor de segurança também participam das reuniôes.

4 Sáo denominados canteiros de trabalho os espaços de empresas que atuam dentro das unidades penais, ofertando trabalho para os privados de liberdade.

\section{Referências}

BRASIL. Lei n.7210 de 11 de julho de 1984: instituí a lei de execução penal. Brasília, 1984. Disponível em: <http://www.planalto.gov.br/ccivil_03/leis/l7210.htm>. Acesso em: 10 fev. 2015.

BRASIL. Constituição (1988). Constituição Federal da República Federativa do Brasil de 1988. Brasília, 1988. Disponível em: <http://www.planalto.gov.br/ccivil_03/ constituicao/constituicaocompilado.htm>Acesso em: 27 de mar. 2019.

BRASIL. Resolução no 14, de 11 de novembro de 1994. Resolve fixar as regras mínimas para o tratamento do preso no Brasil. Disponível em: < http://www.crpsp.org.br/ interjustica/pdfs/regras-minimas-para-tratamento-dos-presos-no-brasil.pdf $>$ Acesso em: 27 de mar. 2019.

BRASIL. Conselho Nacional de Educação. Resolução no 2, de 19 de maio de 2010. Dispóe sobre as Diretrizes Nacionais para a oferta de educação para jovens e adultos em situação de privação de liberdade em estabelecimentos penais. Diário Oficial da União, Brasília, 20 maio 2010. Seção 1, p.20. 
FERREIRA, Maria do Rocio Novaes Pimpão; VIRMOND, Sônia Monclaro. (Org.) Práticas de tratamento penal nas unidades penais do Paraná. Curitiba: SEJU, 2011. (Cadernos do Departamento Penitenciário do Paraná - DEPEN).

MARTINS, Pura Lúcia Oliver. A didática e as contradiçôes da prática. Campinas, SP: Papirus, 2009.

MARTINS, Pura Lúcia Oliver. A relação conteúdo-forma: expressão das contradiçôes da prática pedagógica na escola capitalista. In: VEIGA, Ilma Passos Alencastro (Org). Didática: o ensino e suas relaçóes. Papirus: Campinas, 2011. p.77-103.

PARANÁ. Estatuto Penitenciário do Estado do Paraná: Decreto Estadual no. 1276 de 31 de outubro de 1995.Curitiba, 1995. Disponível em: <http://www.depen.pr.gov.br/ arquivos/File/Estatuto_Penitenciario__1.pdf $>$. Acesso em: 27 de mar. 2019.

PIMENTA, Selma Garrido. (Coord.) Pedagogia, ciência da educação? São Paulo: Cortez, 2006.

SACRISTÁN, Gimeno. Consciência e ação sobre a prática como libertação profissional dos professores. In: NÓVOA, António. Profissão Professor. Portugal: Porto Editora, 2014. p.63-92.

SANTOS, Oder José dos. Pedagogia dos conflitos sociais. Campinas: SP, Papirus,1992.

SILVA, Roberto da; SOUZA NETO, João Clemente de; MOURA, Rogério Adolfo de. Pedagogia Social. São Paulo: Expressão e Arte Editora, 2014. v.1. p.270-289.

SCHMIED-KOWARZIK, Wolfdietrich. Pedagogia dialética: de Aristóteles a Paulo Freire. Tradução: Wolfgang Leo Maar. São Paulo: Editora Brasiliense, 1983.

THOMPSON, E. P. A miséria da teoria ou um planetário de erros: uma crítica ao pensamento de Althusser. Rio de Janeiro: Zahar Editores, 1981.

VÁSQUEZ, Adolfo Sánchez. Filosofia da práxis. Consejo Latinoamericano de Ciências Sociales - CLACSO; São Paulo: Expressão Popular, 2007. Tradução: María Encarnación Moya.

Recebido em Io jan. 20I9 / Aprovado em Io mar. 2019

\section{Para referenciar este texto:}

OLIVEIRA, S. B. A formação do pedagogo para atuar no sistema penitenciário. EccoS-Revista Científica, São Paulo, n. 48, p. 175-197. jan./mar. 2019. Disponível em: <https://doi.org/I0.5585/EccoS.n48.13245>. 
